\title{
Uses of Places and Setting Preferences in a French AntarcticStation
}

Karine Weiss, Marie Feliot-Rippeault and Richard Gaud

The various uses of space as well as the environmental preferences of wintering people were investigated during 1 year in a French Antarctic station using daily participant observation (for uses of places) and a repeated measure of the perception and evaluation of the settings. The uses of places varied according to occupational and age subgroups: The young scientists expressed a higher need for privacy and a strong investment in their working areas, whereas the technicians preferred the social leisure area (main hall). These places were used as different behavior settings and thus corresponded to flexible environments. Flexibility was a characteristic of all the preferred places. A change in the preferences among the settings and the uses of places was also observed: After midwinter, the preferences evolved from private places to working areas. At the end of the mission, a behavioral change reflecting a stronger need for privacy was also observed.

Keywords: adaptation; isolated and confined environments (ICE); habitability;privacy; behavior settings

Everyday life usually takes place in various partial institutions: home,working areas, leisure places, and so on. This division of space correspondsto a separation and a specialization of the places according to theactivities that take place in each behavior setting (Barker, 1968) along witha temporal pattern. This stresses in particular an essential differencebetween public and private territories, which is linked to individual balance, because people need to manage their own private space (Prost, 1987).Moreover, the differentiation of places is related to different social normsattached to them. This repartition of activities is almost nonexistent in isolatedand confined environments (ICEs), which are more characteristic of a "total institution" (Goffman, 1961), where all the functions are linked toone unique institutional space, more or less confined. Thus, these total institutionalspaces constitute places where a small group lives and works, cutoff from the outside world, for a relatively long period. This cloistered lifeis explicitly and systematically regulated by an external authority. Totalinstitutions are both a residential community and a regulated organization(Goffman, 1961). Therefore, they constitute settings where people have tospend all their time, including their working, leisure, and private activities.To live in such an environment during a relatively long period means thatall the usual activities are carried out in a limited space with no clear spatialborders. We already know how useful both the separation of variousspaces according to their functions and the use of spatial borders are to regulatethe level of social interactions or privacy (Carrère\& Evans, 1994).Moreover, in normal environments, social interactions are linked to numerousrelational networks, and these networks reflect the various social rolesin which people are involved according to their activities. People thusdivide up their everyday life among these groups, inside of which they playdifferent social roles. The groups offer at the same time a large variety ofsocial relationships and the possibility of coming into them or withdrawingfrom them according to the individual's mood and objectives. Typically, the individual arriving in the ICE is removed from his or her accustomedsocial circles and put into a strange situation with a group, usually afairly small group, of relative or absolute strangers. Behavior settings in theICE are much less differentiated than back home, with the same people servingas occupational colleagues and off-duty companions. As a 
result, roleexpectations may become confused and both the guidelines for one's ownbehavior and one's ability to predict the behavior of others are eroded. (Suedfeld, 1998, p. 99)

Consequently, we often observe a deterioration of interpersonal relationships.In general, the study of confined groups highlights an increase inwithdrawal, territorial behaviors, and intragroup conflicts, which seem tobe related to crowding and the absence of privacy (Harrison \& Connors,1984). Most of these conflicts result from the exaggeration of trivial issues(Stuster, 1996). Moreover, interpersonal conflicts, anger, and irritabilityseem to be linked to several reasons, such as different organizational status,goals, values, or cultural backgrounds (Gunderson \& Nelson, 1963; Peri, Barbarito, Barattoni, \& Abraham, 2000). It can also happen that winteringpeople within their own mission identify subgroups on the basis of recreationalpreferences or areas of the station where each subgroup spends mostof its leisure time (Johnson, Boster, \&Palinkas, 2003). Privacy regulationthus plays a particular role because people have to manage places at thesame time according to different activities that take place and especiallyaccording to the presence of others. Indeed, the social situation constitutes adouble constraint: On one hand, people undergo social isolation from theirusual environment, and on the other hand, they are subjected to the continuouspresence of others. Personal space, then, is a refuge from the cumulativestress of the mission and near-constant interpersonal exchange (Stuster,1996). Thus, privacy is usually described as a crucial issue for the habitabilityof the ICEs: The most frequently asked question regarding the habitabilityof ICEs concerns spatial requirements.

We can find various definitions of privacy. Some of them emphasize theopportunity of withdrawal and the avoidance of interactions (Bates, 1964);others bring into evidence the freedom in controlling these interactions(Westin, 1970). Obviously, in ICEs where the confinement is extreme, suchas on submarines or manned spaceflights, privacy is a critical issue. Forinstance, the lack of sufficient personal territory for submariners is a primarysource of stress (Serxner, 1968). If we consider that privacy means withdrawalfrom social solicitations and the need to remove oneself occasionallyfrom the company of others, it should not really be a problem in Antarctic stations,because wintering people have at least a private bedroom, which makesit possible to be isolated from the company of station mates. However, privacyis not necessarily linked to personal space. Even if a personal space (i.e.,a bedroom) is available, privacy can be a problem. Indeed, privacy regulationdoes not mean only to be alone or to withdraw; it is a private access to the selfor to a group (Altman, 1975). Privacy issues can thus be linked to differentkinds of territories: private as well as public ones. Territoriality expressesitself by the appropriation and the control of access to these places (Edney,1975). In a polar station, subgroups can appropriate some parts of the environmentby choosing activities linked to these places and shared by themembers of the subgroup. Then, people in ICEs express a need for privacythat most of the time corresponds to the regulation and the maintenance of anoptimal level of social interaction (Altman, 1975). The constant interpersonalcontact in an ICE is highly stimulating, and people need to get awayfrom constant close contact with others. "It is a normal and healthy copingmechanism that helps individuals to adjust to the many stressors of isolatedand confined living" (Stuster, 1996, p. 272). This desire to withdraw from therest of the crew not only is a need for solitude or the wish to rest in one's bedroom but can be expressed by the possibility to meet a chosen subgroup in arecreational area or to perform some solitary activities, including contemplation of the landscape or work. However, even though we know that this questionof privacy is a critical factor for life in ICEs, very few studies haveanalyzed it in a systematic way. Carrère and Evans (1994) showed that designqualities important in an Antarctic setting are the need for privacy, 
flexiblebehavioral settings, and distinct work, recreational, and berthing areas. Theneed for distinct areas is also considered a privacy issue because it allowspeople to get away from one another. Thus, some Antarctic personnel findsufficient private time in their shared quarters; for others, a laboratory workarea provides the solitude they need (Stuster, 1996). Even though in someresearch privacy is not mentioned as an important factor (Stuster, Bachelard,\&Suedfeld, 2000), group interaction seems in fact to be a critical variable inthese studies. Both conditions, social and spatial, are inextricably interdependentin the individual-environment relationship. This has something to dowith the reason that interpersonal problems between members of isolated andconfined groups seem to be inevitable.

As Carrère and Evans (1994) noted, "very little is currently known abouthow occupants of ICEs use these habitats or how they feel about them" (p.738). The present research aims to analyze the various uses of space as wellas the environmental preferences of wintering people during their stay in anAntarctic station. The purpose is also to stress the changes in these behaviorsand perceptions of the environmental and social situation. We hypothesizedthat the behaviors and perceptions of the environment change throughout thewinter-over. If the "third-quarter phenomenon," described as a period of significantemotional changes (Bechtel \&Berning, 1991), has not been foundsystematically in all polar missions (Palinkas, 2000), the end of the winteroverseems to correspond to deep changes in the individual-environment relationship(Weiss, 2005). Some researchers have pointed out the link betweenthe end of the mission and essentially thymic reactions but not social reactions(Décamps\&Rosnet, 2005). However, in accordance with what hasbeen observed in the analysis of the formation and transformation of socialnetworks (Weiss \& Gaud, 2004), we hypothesized that the end of the missionshould correspond with a change in behaviors linked to the occupation ofbehavioral settings, thus revealing a more significant need for privacy and areorganization of the individual-environment relationship (Wapner\& Craig-Bray, 1992). Indeed, the approach of the end of the mission seems to beassociated with a falling off of courtesy in small, isolated crews:With the endof the cohabitation, people allow themselves to express opinions and feelingsthat can be sources of tension (Sandal, 2001).More precisely, the goals of this research, carried out in the Dumont d'Urville polar station, are to determine the following:

- the use that wintering people make of the different settings in the station(what places are most often attended; what are the main social areas; what places are diverted from their original functions, etc.)

- the individual strategies used to preserve a satisfactory level of privacy(through, for instance, different kinds of space appropriation)

\section{Method}

\section{Setting}

Data were collected at the French polar station of Dumont d'Urville inAntarctica. Each year, this permanent scientific station accommodates between 25 and 35 winter-over people, split between general services, scientific departments,and ensuring data collection for the French laboratories working onpolar programs. The total area covered by buildings is $5000 \mathrm{~m} 2$. During thewinter, each person has a private room (about $9 \mathrm{~m} 2$ ). All the bedrooms arelocated in the same building, which also accommodates the bathrooms, thehospital, and the leader's office. Bedrooms are the only 
private space. Theother place for relaxation is the main hall, which contains the kitchen, the diningroom, the bar, the living room (with a library, games, and sofas), andanother room with a video library. The dining room functions as differentbehavior settings according to the time schedule: After dinner, it becomes arecreation room or a cinema. Working areas are distributed in buildingsaround the main hall. The scientific activities take place in laboratories, where the scientists work in small groups. However, most of the scientistshave the possibility to manage, in their working area, a personal space. Someof them even have an office considered as a private space. However, most ofthe technicians do not have this opportunity of having a quiet working area.Indeed, even those who have their own place (garage, workshops) have tocarry on their duties in the various buildings of the station or outside.

\section{Data Collection}

A systematic observation was made by the medical officer of the missionduring a winter-over at Dumont d'Urville Station.1 This observation allowedfor the collection of data about the frequency of use of the different places ofthe station. These specific and repeated statements took place in the commonrecreational place of the station. They mention where each crew member isand, as far as possible, indications relating to their activities along with their social or withdrawal behaviors in particular. Every day, two observationswere made, at 8:30 p.m. and 10:30 p.m. The dinners generally finishedaround 7:45 p.m., and the food service ended around 8:15 p.m. At this time,people decided what kind of activity they were going to do during theevening. Between 10:30 and 10:45 p.m., the situation could change and a secondactivity could start. The observation began the day before the last shipleft the station and finished 9 months later, the day before the arrival of thenew wintering crew. One month before, the boat had brought men from thesummer staff, who did not stay in the station. Some of them were going tothe Concordia station (inside the Antarctic continent), and the others weregoing to the Prudhomme station, a smaller facility that functions only duringthe summer and is a few kilometers away from Dumont d'Urville.A second set of data was collected in parallel, also during the wholewinter-over period: Every 2 months, questionnaires were filled out by the participants,that is to say, six times between January and December. The firstand the last data collection period corresponded to summer periods, when thestaff was more numerous at the station because of transitions between old andnew teams and because of the presence of specialized workers for the summer.The questionnaire related to the appreciation and the use of the placesby wintering people: They were asked to specify the places where they spentmost of their time, those that they preferred, those where they preferred beingalone, and finally, places where they preferred being in the company of others.

For each question, a maximum of five places could be mentioned. In thepresent study, we analyzed only the first-mentioned place for each question.Four kinds of places appeared in the answers:

- the main hall (dining room, bar, living room)

- the working areas (scientific laboratories and technical workrooms)

— the bedrooms (the dormitory building as well as the individual bedrooms)

- outside (areas where people go walking or contemplating the landscapeor the animals) 
The respondent then indicated the reasons he chose those places. A content analysis of the answers allowed for the categorization of these reasonsaccording to qualities and activities associated with each place. Wegrouped them into seven main categories:

- rest (relaxation, rest, comfort)

- work (own work as well as work of other people in the station)

— sociability (social games, discussions, informal meetings, etc.)

- leisure (only solitary leisure, such as reading, sport, etc.)

- contemplation (landscape, meditation)

- diverse (more than one activity was mentioned; most of the time, a solitaryactivity was associated with a social one)

— privacy (for the places where people like to be alone)

\section{Participants}

The wintering team was made up of 27 men (from 21 to 59 years old; $M=31.8$ ), including the medical officer who collected the data. Becausethis position of participant-observer could constitute a bias, we removedhim from the analysis. We identified two subgroups according to age and tooccupational activity:

- Within the first subgroup, there were 14 participants (54\% of the wholecrew). They constituted the older subgroup ( $M=37.8$, range $=30$ to 59).All the subjects in this group were from the technical staff, with 11 personsfrom the technical support team (average age $=35.4$ years) and 3 men from the meteorology survey team (average age $=51.7$ years). Forty percent of this group had already wintered once.

- The second subgroup was made up of 12 scientists ( $46 \%$ of the total group), who were performing their military duty as volunteers for scientificresearch. All of them were younger than the first subgroup participants $(M=24.3$, range $=20$ to 27) and were staying in Antarctica for the first time.Thus, age and occupational status were two confounded factors. Weknow that these factors are often linked to the emergence of subgroups inthe French winter-over stations and also sometimes to intergroup tensionsor conflicts (Weiss \& Gaud, 2004). Indeed, these subgroups usually havedifferent interests, leisure activities, and goals and develop different waysof experiencing their winter-over. We have therefore used these factors as independent variables for the analyses. We did not analyze other variables such as previous Antarctic experienceor marital status of the subjects, even though these variables could have beenrelevant. For instance, only some of the older participants had a previousAntarctic experience, and we know that novices and old hands have differentrelationships with the Antarctic environment (Steel, 2000). The subgroup oftechnicians was too small to split it again between novices and old hands.

All the crewmates were included in the observation sessions, but someof them did not want to answer the questionnaires. For this set of data, thenumber of respondents varied between 19 (70\%) and $21(78 \%)$, dependingon the month. 


\section{Table 1}

Mean Percentages for Place Occupation in the Evenings During the Winter-Over (From the Observation)

\begin{tabular}{lcccc}
\hline Group & Main Hall & Bedroom & Working Area & Outside \\
\hline Scientists & 40.28 & 30.32 & 28.45 & 0.96 \\
Technicians & 35.81 & 33.65 & 30.08 & 0.45 \\
Total & 37.79 & 32.17 & 29.36 & 0.68 \\
\hline
\end{tabular}

\section{Results}

\section{Places Occupation}

Broadly during the whole mission, at 8:30 and 10:30 p.m., the main hallwas the place where most of the winter-over participants stayed (37.79\%). The other winterers remained either in their bedroom (32\%) or in the workingareas (29\%). Fewer than $1 \%$ went out for a walk (Table 1).The occupation of the settings in the station was different according to thetwo occupational and age groups: The young scientists stayed in the main hallmore often than did the technicians $(x 2=31.62, p<.001)$. They also wentoutside more often $(\chi 2=14.06, p=.0002)$. The technicians remained morein their bedrooms or in the work places $(\chi 2=38.89, p<.001)$.Among the participants who were not in the main hall, we gathered data onthose who were elsewhere for professional reasons and those who left for personalreasons. Indeed, some of them were constrained by professional obligations, and we were more interested by personal choices, that is, with peoplewho were elsewhere (even in the working areas) for nonprofessional reasons. The main hall is the privileged place for informal meetings of the whole group.So when winterers are away from this place for personal reasons, they havechosen to remove themselves from the company of the crew, wherever theselected place: bedroom, outside, or working place. In all these places, theycould be alone or meet with subgroups, but it was impossible for us to checkthis last point. People from the two subgroups were outside the main hall mostoften for personal versus professional reasons. Yet the technicians left thisplace more often than the scientists both for personal reasons $(54.01 \%$ vs.51.54\% for the scientists group) and for professional motives ( $10.18 \%$ vs.8.18\% for the scientists group). The difference between the two subgroups wassignificant $(\chi 2=39.97, p<.001)$. Among the crewmates who were outside themain hall for personal reasons, $60.81 \%$ were in their bedroom, $37.92 \%$ were ina work place, and $1.28 \%$ were outside for a walk. Concerning this last distributionof activities, there was no difference between the two groups.

\section{Setting Preferences}

In addition to the observations that were made daily at a specific time,there were questionnaires relating to attended places and preferences linkedto them in a global sense. The participants answered with reference to theiractivities during the whole day. This difference did not allow for a comparisonof the two sets of data but made complementary information available. 
For all the winterers, the most often used place was the work place $(85.94 \%$ for the scientists, $81.48 \%$ for the technicians; $n s)$. For the scientists, this place was also where they preferred to be $(\chi 2=7.038$, $p=.008)$.In contrast, the technicians answered that they preferred the main hall; thedifference between the two groups is also significant, $\chi 2=13.69, p=.0002$. There was a tendency for the younger group (the scientists) to appreciatethe outside more than there was for the technicians, $\chi 2=$ 3.18, $p=.07$ (ns).Last, the appreciation of the bedrooms was almost the same in the twogroups, and the difference was not very large (Table 2).

With reference to the activities associated with each of these places, contemplationand meditation were the most preferred activities for the scientistsgroup, that is, the most frequently mentioned reasons in associationwith the favorite place (Table 3 ). Outside was related mainly to these activities $(93.3 \%$ of the answers that were associated to the outside as thefavorite place mentioned contemplation or meditation); also, the bedroomswere mainly connected with this kind of solitary behavior (83.3\%). Withinthe technicians group, we did not find the same kind of predilection: Theanswers categorized as diverse (i.e., social as well as solitary activities)were most often related to the chosen place (33.3\%).

The working areas, which were the favorite places for the scientists, were not associated with a particular activity or quality. On the contrary,they seemed to be varied insofar as almost all the activities (except contemplationand meditation) were associated with them in an equivalent way. This result seems to correspond to the concept of flexibility evoked byCarrère and Evans (1994).

Table 2

Mean Percentages for Favorite Place (Mentioned as the First Preferred Place) During the Mission

\begin{tabular}{lcccc}
\hline Group & Main Hall & Bedroom & Working Area & Outside \\
\hline Scientists & 11.11 & 11.11 & 53.97 & 23.81 \\
Technicians & 40.74 & 18.52 & 29.63 & 11.11 \\
Total & 24.79 & 14.53 & 42.74 & 17.95 \\
\hline
\end{tabular}

Table 3

Mean Percentages for Activities or Qualities Related to Favorite Place During the Mission for the Scientists

\begin{tabular}{lrrrcrr}
\hline Place & Sociability & Rest & Diverse & Contemplation & Work & Leisure \\
\hline Main hall & 33.33 & 0.00 & 50.00 & 0.00 & 0.00 & 16.67 \\
Bedroom & 0.00 & 16.67 & 0.00 & 83.33 & 0.00 & 0.00 \\
Working area & 17.86 & 14.29 & 25.00 & 0.00 & 28.57 & 14.29 \\
Outside & 0.00 & 0.00 & 0.00 & 93.33 & 0.00 & 6.67 \\
Total & 12.73 & 9.09 & 18.18 & 34.55 & 14.55 & 10.91 \\
\hline
\end{tabular}


Table 4

Mean Percentages for Activities or Qualities Related to Favorite Place During the Mission for the Technicians

\begin{tabular}{lrrrrrr}
\hline Place & Sociability & Rest & Diverse & Contemplation & Work & Leisure \\
\hline Main hall & 36.36 & 4.55 & 54.55 & 0.00 & 0.00 & 4.55 \\
Bedroom & 0.00 & 60.00 & 10.00 & 20.00 & 0.00 & 10.00 \\
Working area & 6.25 & 6.25 & 31.25 & 6.25 & 37.50 & 12.50 \\
Outside & 0.00 & 0.00 & 0.00 & 100.00 & 0.00 & 0.00 \\
Total & 16.67 & 14.81 & 33.33 & 16.67 & 11.11 & 7.41 \\
\hline
\end{tabular}

As for the scientists, the outside was always considered by the technicianswho had chosen it as a favorite place, to be a good place for contemplationand meditation. But for this group, the bedrooms were more relatedto rest (60\%) than to meditation (20\%). Working areas were above all viewed by this group as places where professional activities have to be performed(37.5\%), but they could also be associated with other, more personalactivities (diverse; 31.25\%). They thus constituted settings that forthis group again could be associated with nonprofessional activities,although to a lesser extent than for young people (Table 4).

Table 5

Mean Percentages for First Place Winterers Preferred to Be Alone During the Mission

\begin{tabular}{lccc}
\hline Group & Bedroom & Outside & Working Area \\
\hline Scientists & 47.54 & 29.51 & 22.95 \\
Technicians & 67.31 & 15.38 & 17.31 \\
Total & 56.64 & 23.01 & 20.35 \\
\hline
\end{tabular}

Table 6

Activities Associated With the Place Scientists Preferred to Be Alone

\begin{tabular}{lrrcrrr}
\hline Place & Leisure & Rest & Contemplation & Privacy & Work & Diverse \\
\hline Bedroom & 8.00 & 32.00 & 12.00 & 44.00 & 0.00 & 4.00 \\
Outside & 0.00 & 38.89 & 55.56 & 5.56 & 0.00 & 0.00 \\
Working area & 10.00 & 10.00 & 0.00 & 40.00 & 20.00 & 20.00 \\
Total & 5.66 & 30.19 & 24.53 & 30.19 & 3.77 & 5.66 \\
\hline
\end{tabular}

The place where the winterers preferred mainly to be alone was their ownbedroom. It corresponded to a preferential private space, and this predilectionwas more accentuated for the technicians $(\chi 2=$ 4.466, $p=.03$ ). For the scientistsgroup, outside was also a place where they liked to be alone. Yet thedifference with the other group corresponded to a tendency that was not significant $(\chi 2=3.16, p$ $=.07$ ). Last, the working areas were also mentioned asone of the places where both groups liked to be alone (Table 5).In response to the question Why did you choose this place? a new categoryof 
answers appeared: the need for privacy. Thus, wherever the chosen setting,privacy and rest were the main reasons used to describe the place where theyoung scientists preferred to withdraw from the group (30.19\% of the answersfor each of the two reasons). Privacy was associated with both the bedroomand with the workplace ( $44 \%$ and $40 \%$, respectively, for the associations). Relaxation and rest were slightly more often associated with the outside $38.89 \%)$ than with the bedroom $(32 \%$ of the answers; see Table 6).Privacy seemed to be less important for the technicians than for the scientists $(9.62 \%$ vs. $30.19 \% ; \chi 2=6.94, p=.008)$. Moreover, privacy wasrelated only to the bedroom. Rest corresponded to the activity most oftenassociated with the withdrawal places. It was a little more frequently citedthan in the younger group ( $40.38 \%$ of the total answers, $n s)$ and also related to the bedroom (Table 7).

\section{Table 7}

Activities Associated With the Place Technicians Preferred to Be Alone

\begin{tabular}{lrrcrrr}
\hline Place & Leisure & Rest & Contemplation & Privacy & Work & Diverse \\
\hline Bedroom & 14.29 & 54.29 & 2.86 & 14.29 & 0.00 & 14.29 \\
Outside & 0.00 & 12.50 & 87.50 & 0.00 & 0.00 & 0.00 \\
Working area & 0.00 & 11.11 & 11.11 & 0.00 & 33.33 & 44.44 \\
Total & 9.62 & 40.38 & 17.31 & 9.62 & 5.77 & 17.31 \\
\hline
\end{tabular}

The last question was about the settings where the participants preferredto be accompanied. For this last point, there was no difference between thetwo occupational and age groups: All the winterers chose the main hall(65.52\% of the answers), followed by the working area (29.03\% of theanswers for the scientists, $25.93 \%$ for the technicians). Both the bedroom andoutside accounted for approximately $3 \%$ of the choices. There was also nodifference between the two groups for the related activities or qualities: Mostof the crewmates linked social activities with these places $(63.89 \%$ for thescientists; $52.94 \%$ for the technicians) or associated social and other kinds ofactivities (diverse; $25 \%$ for the scientists, $38.24 \%$ for the technicians).

\section{Changes in Occupied Places and Setting Preferences}

One of our hypotheses was about the changes in behaviors and perceptionsrelated to the environment. In accordance with what has been highlightedin a great deal of research, we observed that the end of the winter-overwas characterized by a specific configuration: After a period during which thebehaviors related to the uses of places had been relatively stable, the main hallseemed to be forsaken, and other places were more used, primarily for personalpurposes. There was no difference between the two studied subgroups(Figure 1). However, places associated with personal activities remained thesame: They were, throughout the winter-over, in the same proportions: thebedroom, then the workplace, and then the outside. Only this last categoryslightly increased during the last 2 months, which corresponded to theincreased possibilities to go for a walk close to the station outside, even in theevening, thanks to the longer daylight and the mild climate during this periodof the year. 


\section{Figure 1 \\ Changes in the Use of Different Places During the Winter-Over for the Two Occupational Subgroups}

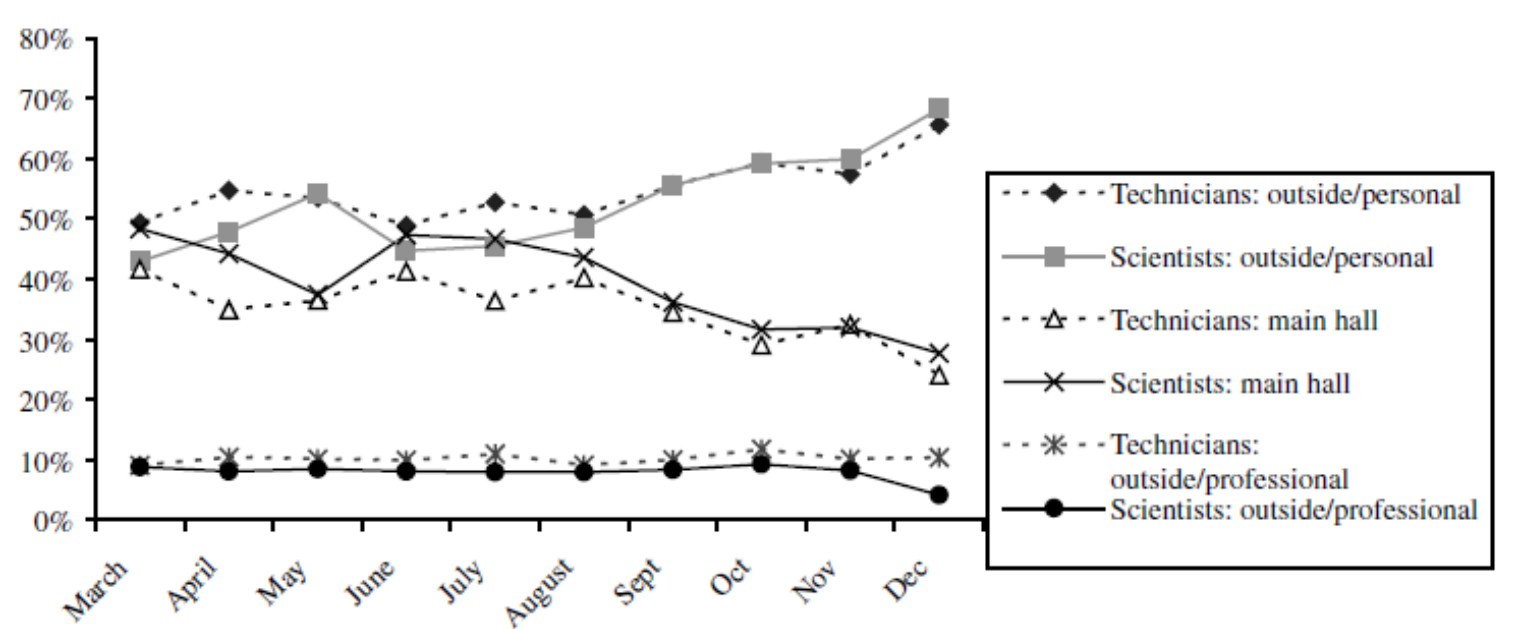

With regard to the preferences associated with the places, it was verydifficult to observe the possible changes with only one measurement every 2 months. The number of participants was too small to draw any conclusionsabout an evolution. Moreover, comparing the two occupational subgroupswas problematic because of individual variations. The only tendencythat seemed to appear was about the place where winterers preferred to bealone: The bedroom was highly chosen at the beginning of the mission(72.22\% of the choices in January and $66.67 \%$ in March and May); aroundmidwinter, in July, it was less chosen (36.84\%), and the working area wasthen preferred as a private place $(45.37 \%)$. At the end of the year, the bedroombecame again the privileged personal space (55.56\%). At this time,we could also observe a preference for outside, which may again be linkedwith the good weather, the daylight, and the presence of emperor penguinsnear the station (Figure 2).

\section{Discussion}

As in a previous study on the formation and transformation of relationalnetworks (Weiss \& Gaud, 2004), data resulting from the observations andfrom the questionnaires were not directly comparable: The frequencies ofthe collections were not the same. However, they allowed for the gatheringof two coherent and complementary sets of data, which made it possible to,understand why and how uses of space and especially privacy management played a significant role for people who were living in an ICE. These sets also allowed us to study the relation between social and spatial behaviorsand needs. Indeed, the frequency of the observations made it possible tostress the changes in the behaviors, whereas the questionnaires supportedknowledge about how winterers globally perceived their living environment.The two sets of indicators highlighted different uses of the placesaccording to the two occupational subgroups, which also corresponded toage subgroups. 
Figure 2

Changes in the Choice of Place Where

Winterers Preferred to Be Alone

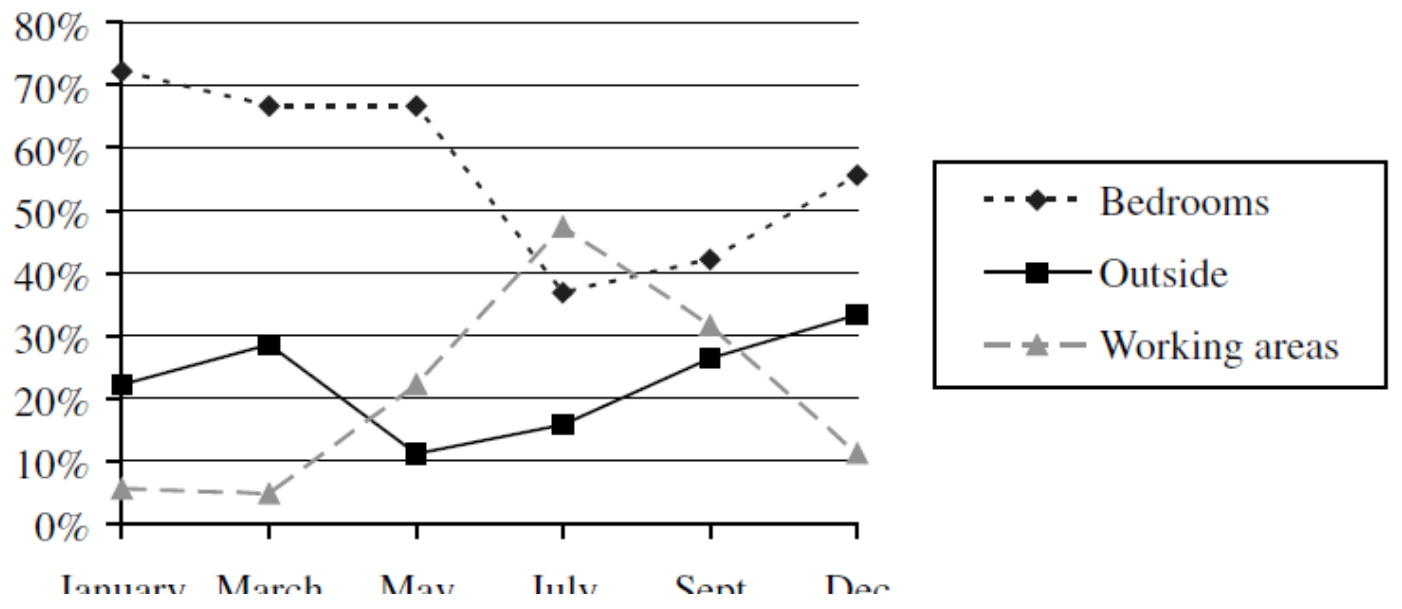

These two groups seemed to have different expectations andneeds in terms of interpersonal relationships, privacy, and space occupation. We already knew that the tensions or conflicts that usually occur inpolar stations generally correspond to intergroup tensions, reflecting asocial categorization related to professional statutes, in particular, becauseof different values, goals, and activities shared by the subgroups (Stuster etal., 2000; Weiss \& Gaud, 2004). But "the formation of subgroups is a naturalphenomenon and can contribute to individual adjustment, if not permittedto develop to the extreme" (Stuster et al., 2000, p. A25). Thus, theobservation revealed that during the evening, after the meal, the young scientistshad more of an investment in the main hall than did the technicians. This place indeed seemed to be associated with a recreational time, whensocial activities were privileged. On the contrary, at evening time, the olderparticipants used this place, their private room, or their working place in anequivalent way. But paradoxically, they generally chose the main hall as their favorite place in the station. This apparent contradiction seemed to berelated to the difference in temporal scales used within the questionnaires(every 2 months) and the observations (twice a day): The related occupationswere not the same all day long, and maybe this subgroup would havepreferred the main hall and its recreational activities at another period of theday. As we have said before, this place corresponds to several behavior settingsin accordance with temporal boundaries, for instance, a movie theateronce a week, a bar before and after meals, a recreational area at night, anda dance hall on Saturday nights.

The analysis of the preferences of the scientists group shows a very stronginvestment in the working areas. These places indeed constituted for them atthe same time a private space and a friendly place for recreational activities.They therefore corresponded to flexible environments because they alloweddiversified activities. This flexibility was indeed a common characteristic ofthe participants' favorite places in a general way and not only of the workingplace. This corresponds to an important result already highlighted by Carrèreand Evans (1994). In the present research, flexibility is linked not to the possibilityof rearranging the places but to performing different kinds of activitiesin the same place and, moreover, to the possibility of using these placesalone as well as within small subgroups. So habitability studies may considerplaces not only as physical spaces but as behavior settings, that is, spatial andsocial situations temporally bounded in which behaviors are essential for thesystem's 
definition (Barker, 1968). For instance, the working area was, for thescientists, very much related to privacy: The working place was associatednot only with professional activities but also with social behaviors and withprivacy. Depending on the temporal boundaries, it played the role of three differentbehavior settings, and in this way, it was a highly flexible place.

In all the cases, privacy was linked to withdrawal: This category ofanswers appeared only in association with the places where the winterers preferredto be alone. Privacy was much more important to scientists, for whomit constituted, in addition to rest, the first connection made with solitaryplaces (30\% of the elicitations). For the technicians, privacy accounted foronly $9 \%$ of the answers to this question. In addition, in the scientists' group,privacy was associated equally with the bedroom and with the working place,whereas it was exclusively related to the bedroom in the technicians' group.These results brought to light a considerable difference related to expectationsin terms of social contacts in the two groups: The younger groupseemed to need times and places privileging the social life (as shown withtheir uses of the main hall) as well as times and various places allowing themto reach a satisfying level of privacy. For the older group, privacy was not mentioned very frequently, and it was associated only with their real personalspace, the bedroom. The desired level of interactions was not the same forboth groups, and we know that well-being is associated with a balancebetween desired and achieved levels of social interaction (Evans, Rhee,Forbes, Mata-Allen, \&Lepore, 2000). Thus, results from other research sharingthe social categorization in ICEs (Weiss \& Gaud, 2004) could be to a certainextent explained by these different needs in terms of privacy and socialcontacts. Indeed, space management in these conditions of isolation and confinementcorresponds to a management of both privacy and social relationships.In the present study, it was linked to two different styles of placeoccupation related to the occupational and age subgroups, which had differentexpectations about these places. That is why each place seemed to correspondto various behavior settings that differentiated these subgroups.

In addition, there was a change in the preferences and uses of the places:A seasonal variation was observed only for the places where people likedto be alone. Uses of places and expressed preferences demonstrated the difficultieslinked to privacy. It seemed difficult to appropriate and to protectone's personal space. Around midwinter, the favorite private place, whichwas previously the bedroom, became the working place and later becamethe bedroom once again at the end of the mission. This change is also characteristicof the need for privacy, which is usually not satisfied in an ICE.Indeed, on one hand, in the Dumont d'Urville station, the bedrooms are notsoundproof and are small (about $9 \mathrm{~m} 2$ ). They were usually not mentionedas pleasant places. On the other hand, work places do not constitute a realprivate space, because other people can enter them, whereas in their bedrooms,the winterers can withdraw more easily. In the Carrère and Evans(1994) study, people indicated that they used their rooms as places to bealone because others should not disturb them there. Thus, the winterers'choices about their favorite private places seemed to evolve according totheir need for withdrawal, more significant at the end of the mission (see,for instance, Kraft et al., 2002; Weiss \& Moser, 2000). Moreover, the observationshowed that during the mission, the main hall, which was the onlyplace really used by the entire group, was also forsaken for places withmore withdrawal possibilities. As in previous studies, a behavioral changethus was observed the end of the mission, reflecting a stronger need forprivacy. As we have hypothesized before (Weiss \& Gaud, 2004), thischange could correspond to a process of readaptation at this time becauseat the end of the mission, people had to prepare for their reentry into theirnormal lives and face problems that they had kept away from during theirstay in Antarctica. The management of small, isolated groups 
should take this result into account because it seems essential to envisage more withdrawalpossibilities at the end of missions because of the environment aswell as the activities in which the station mates have to be involved.

\section{Note}

1. The specific year of the study is not given to preserve the confidential nature of the data.

\section{References}

Altman, I. (1975). The environment and social behavior. Monterey, CA: Brooks/Cole.

Barker, R. G. (1968).Ecological psychology: Concepts and methods for studying the environmentof human behavior. Stanford, CA: Stanford University Press.

Bates, A. (1964). Privacy: A useful concept? Social Forces, 42, 432.

Bechtel, R. B., \&Berning, A. (1991). The third-quarter phenomenon: Do people experiencediscomfort after stress has passed? In C.-P. Kay (Ed.), From Antarctica to outer space: Lifein isolation and confinement (pp. 261-265). New York: Springer-Verlag.

Carrère, S., \& Evans, G. W. (1994). Life in an isolated and confined environment: A qualitativestudy of the role of the designed environment. Environment and Behavior, 26(6), 707-741.

Décamps, G., \&Rosnet, E. (2005).A longitudinal assessment of psychological adaptation duringa winter-over in Antarctica.Environment and Behavior, 37(3), 418-435.

Edney, J. J. (1975). Territoriality and control: A field experiment. Journal of Personality andSocial Psychology, 31, 1108-1115.

Evans, G. W., Rhee, E., Forbes, C., Mata-Allen, K., \&Lepore, S. J. (2000).The meaning andefficacy of social withdrawal as a strategy for coping with chronic residential crowding.Journal of Environmental Psychology, 20, 335-342.

Goffman, I. (1961). Asylums. New York: Doubleday.

Gunderson, E. K. E., \& Nelson, P. D. (1963).Adaptation of small groups to extreme environments.Aerospace Medicine, 34, 1111-1115.

Harrison, A. A., \& Connors, M. M. (1984).Groups in exotic environments.In L. Berkowitz(Ed.), Advances in experimental social psychology (Vol. 18, pp. 49-87). New York:Academic Press.

Johnson, J. C., Boster, J. S., \&Palinkas, L. A. (2003).The evolution of networks in extremeand isolated environments.Journal of Mathematical Sociology, 27, 1-34.

Kraft, N. O., Inoue, N., Mizuno, K., Ohshima, H., Murai, T., \&Sekiguchi, C. (2002).Psychologicalchanges and group dynamics during confinement in an isolated environment.Aviation, Space, and Environmental Medicine, 73(2), 85-90.

Palinkas, L. A. (2000). Stages of change in mood and behavior during a winter in Antarctica.Environment and Behavior, 32, 128-141. 
Peri, A., Barbarito, M., Barattoni, M., \& Abraham, A. (2000).The dynamics and the interpersonaland intrapersonal relations within an isolated group in extreme environments. Environment and Behavior, 31(3), 251-274.

Prost, A. (1987). Frontières et espaces du privé [Boundaries and spaces of private life]. InG. Duby (Ed.), Histoire de la vie privée (pp. 13-154). Paris: Seuil.

Sandal, G. M. (2001). Crew tension during a space station simulation.Environment andBehavior, 33(1), 134-150.

Serxner, J. L. (1968). An experience in submarine psychiatry.American Journal of Psychiatry,125(1), 25-30.

Steel, G. D. (2000). Polar bonds: Environmental relationships in the polar regions. Environmentand Behavior, 32(6), 796-816.

Stuster, J. (1996). Bold endeavors: Lessons from polar and space exploration. Annapolis, MD:Naval Institute Press.

Stuster, J., Bachelard, C., \&Suedfeld, P. (2000).The relative importance of behavioral issuesduring long-duration ICE missions.Aviation, Space, and Environmental Medicine, 71(9),A17-A25.

Suedfeld, P. (1998). What can abnormal environments tell us about normal people? Polar stationsas natural psychology laboratory. Journal of Environmental Psychology, 18, 95-102.

Wapner, S., \& Craig-Bray, L. (1992). Person-in-environment transitions: Theoretical andmethodological approaches. Environment and Behavior, 11, 3-32.

Weiss, K. (2005). Adaptation et transitions en milieux inhabituels: Le cas des hivernages dansles bases polaires françaises [Adaptation and transitions in unusualenvironments: The caseof winterovers in French polar stations]. In E. Ratiu (Ed.), Transitions et rapports àl'espace (pp. 47-74). Paris: L'Harmattan.

Weiss, K., \& Gaud, R. (2004). Formation and transformation of relational networks during anAntarctic winter-over. Journal of Applied Social Psychology, 34(8), 1563-1586.

Weiss, K., \& Moser, G. (2000). Aspects relationnels de l'adaptation en milieu confiné: Replisur soi, contagion comportementale et comparaisons sociales [Relational aspects of adaptationin isolation and confinement:Withdrawal, behavioral contagion, and social comparisons].In J. M. Monteil (Ed.), Perspectives cognitives et conduites sociales (Vol. 7,pp. 63-93). Rennes: PUR.

Westin, A. (1970). Privacy and freedom.New York: Atheneum. 